\title{
Epidemiological and quantitative relationships between mesothelioma and asbestos on Tyneside
}

\author{
T. ASHCROFT ${ }^{1}$
}

From the Department of Pathology, University of Newcastle upon Tyne

SYNOPSIS Thirty-five necropsied cases of diffuse malignant mesothelioma of pleura and six cases $\frac{\Omega}{\circ}$ of mesothelioma of peritoneum are reported. Occupational histories from 40 cases showed that

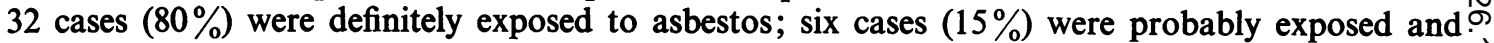
two $(5 \%)$ had no known exposure. The mean latent interval was 34 years. Occupational histories. $\overrightarrow{.}$ of 56 control patients matched in pairs for age and sex with 28 of the mesothelioma cases revealed $\mathbb{N}^{\infty}$ definite exposure to asbestos in 12 controls $(21 \%)$, probable exposure in $11(20 \%)$, and no evidence $\circ$

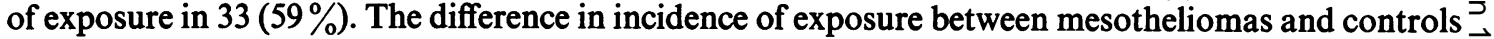
is statistically highly significant. Six-micron histological sections of lung, available in 39 mesothelioma $Z$ cases, contained coated asbestos fibres in 36 cases $(92 \%)$. Sixteen cases of mesothelioma showing fibres were free of asbestosis; asbestosis was slight in 14 cases, moderately severe in five cases, and severe in one case. The incidence of asbestos bodies in sections from mesothelioma cases was significantly higher than in a previously reported series of routine necropsies examined by lung smear.

Counts of coated and uncoated asbestos fibres were performed on samples of lung tissue fro. 33 mesothelioma cases. No fibres were identified in one case and only occasional coated fibres ints second case. The remainder gave counts ranging from 154 thousand to 684 million fibres per gram dry weight. Uncoated fibres were invariably present and usually comprised 50 to $80 \%$ of the count. No relationship was found between total fibre count and the latent period of the mesothelioma.

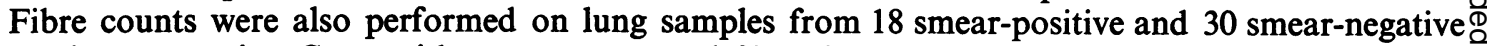
routine necropsies. Cases with numerous coated fibres in the smear gave total fibre counts $\operatorname{similar} \overrightarrow{\overrightarrow{0}}$ to those of mesothelioma cases without asbestosis. Routine cases with only one fibre in the smear 3 usually yielded only occasional fibres on analysis. Coated and uncoated fibres were found in 13 out of 30 smear-negative cases, indicating a true incidence of $56 \%$ of exposure to asbestos in the whole necropsy series. When compared with the mesothelioma series the difference in incidence of fibres remains statistically significant.

The data suggest that, on Tyneside, exposure to asbestos sufficient to cause an appreciable risk $\stackrel{\frac{0}{3}}{\underline{3}}$. of developing mesothelioma has usually occurred through occupational exposure rather than by general environmental pollution by asbestos.

Although noted independently by Weiss (1953), van der Schoot (1958), and König (1960), the association between exposure to asbestos and diffuse malignant mesothelioma first attracted wide attention through the publication of a series of South African cases by Wagner, Sleggs, and Marchand (1960). Subsequent comparisons between cases of this pathologically controversial condition and control patients have, with one exception (Hägerstrand,

${ }^{1}$ Present address: Department of Pathology, Leighton Hospital, Leighton, Nr Crewe, CW1 4QJ.

Received for publication 8 August 1973.
Meurman, and Ödlund, 1968), confirmed a statistically significant association with asbestos $N$ (Hourihane, 1964; Elmes, McCaughey, and Wade, N 1965; Selikoff, Churg, and Hammond, 1965; New-N house and Thompson, 1956; McEwen, Finlayson, $\omega$ Mair, and Gibson, 1970; Whitwell and Rawcliffe, 1971). But although several writers have remarked $\stackrel{\circ}{\complement}$ on the absence of asbestosis and the mildness of $\stackrel{\Phi}{\oplus}$ asbestos exposure in many cases of mesothelioma, $\stackrel{+}{+}$ no estimates of pulmonary asbestos concentration appear to have been made.

The present study explores the relationship $\frac{\stackrel{?}{\Phi}}{\mathbb{Q}}$ 
between mesothelioma and asbestos on Tyneside, with emphasis on quantitative aspects of the association. Preliminary reports of part of the present material have already been published (Ashcroft and Heppleston, 1970; Ashcroft, 1973).

The largest local asbestos consumer is the shipbuilding and repair industry, which has been active on a large scale since before the beginning of the century. Other Tyneside industries use asbestos in the manufacture of products such as floor tiles, brake linings, and insulating mattresses, and a large asbestos factory produces other insulation materials. Asbestos is also imported through Newcastle docks.

\section{Materials and Methods}

\section{MESOTHELIOMA CASES}

\section{Sources of material}

Necropsy records in the principal Tyneside hospitals were examined for cases of pleural or peritoneal tumour with no primary growth in the viscera. The histological sections of all likely cases were reviewed and in those not immediately excluded on morphological grounds, further histochemical investigations were carried out in the Pathology Department at the Royal Victoria Infirmary. Necropsy records from 1948 onwards were generally included but in some departments records before 1958 were not available.

A provisional diagnosis of diffuse mesothelioma was made in 13 cases in surgical histopathological material in the Royal Victoria Infirmary and was later confirmed at necropsy. Postmortem specimens from 13 further cases were received from the Newcastle Pneumoconiosis Medical Panel and six cases were contributed by local pathologists. Biopsies from six additional patients showed microscopic features highly suggestive of mesothelioma, but as necropsy had not been performed they have bsen excluded from this study. Collection of cases ceased in September 1969.

\section{Asbestos exposure}

After a case had been accepted on pathological grounds as a mesothelioma, evidence of exposure to asbestos was sought by investigating the occupational history. When a provisional diagnosis was made during life, a full occupational history was obtained by personal interview. Otherwise, the patient's relatives were interviewed. During all interviews, enquiries were also made about non-occupational exposure to asbestos. Occupational information for some patients was obtained from the Pneumoconiosis Medical Panel.
Evidence of asbestos exposure was also sought by systematic microscopic examination of 6-micrometer $(\mu \mathrm{m})$ paraffin sections of lung tissue for coated asbestos fibres (asbestos bodies). Coated fibres were counted as 'scanty' when they were found only infrequently on traversing a slide and as 'numerous' when they could be found without difficulty in many fields. The degree of asbestosis was also noted and this aspect is more fully described elsewhere (Ashcroft and Heppleston, 1973). When sufficient lung tissue was available counts of coated and uncoated asbestos fibres were carried out using an alkali digestion technique resembling that of Gold (1968) but differing in several important respects (Ashcroft and Heppleston, 1973).

\section{MATCHED CONTROL PATIENTS}

The occupational histories of the mesothelioma patients were compared with those of matched control patients who were free of malignant disease. For each of the 28 mesothelioma patients identified up to mid-1967, two controls of the same sex and within five years of the same age were selected from the records of the hospital in which the propositus had died or received treatment. A more detailed occupational history can generally be obtained from a patient in person than from the relatives of a deceased patient, and to avoid possible bias arising from this fact controls for 11 mesothelioma patients who had been interviewed in life were chosen from admission records and were also interviewed in person. Occupational histories for 17 necropsy cases of mesothelioma had been secured from relatives, and histories were obtained in the same way for their controls, chosen from necropsy records. No account was taken of the diseases from which control patients suffered, apart from excluding malignancy. As before, nonoccupational asbestos exposure was also considered.

\section{ROUTINE NECROPSIES}

The incidence of coated fibres in $6 \mu \mathrm{m}$ lung sections of mesothelioma was compared with that in basal lung smears prepared at $\mathbf{3 1 0}$ routine necropsies in the Royal Victoria Infirmary (Ashcroft, 1968a). Asbestos fibre counts were performed on samples of lung tissue from nine routine cases with numerous coated fibres in the smear, from nine cases with one coated fibre in the smear, and 30 smear-negative cases.

\section{Results}

MESOTHELIOMA CASES

Thirty-five cases were accepted as mesothelioma of pleura and six cases as mesothelioma of peritoneum. 
Thirty-six patients were male and five patients, all with pleural tumours, were female. The average age was 57 years, with a range of 42 to 76 years. The tumour arose in the left pleura in 14 patients and the right pleura in 21 patients. Twenty-five tumours were of mixed epithelial and mesenchymal variety, 12 were purely epithelial, and four were purely mesenchymal.

\section{Occupational histories}

The evidence for exposure to asbestos derived from occupational histories and lung sections is summarized in table I.

A history was not obtained for case 3 , since no living relative could be traced, but some information was obtained for each of the remaining cases and in most instances a reasonably full history was available. The patients fall into three groups:으 those with (1) definite exposure to asbestos; (2) $\vec{F}$ probable exposure; (3) no known exposure.

Group 1 consists of 32 persons definitely exposed to asbestos (table I). All received their exposure $\overline{\bar{C}}$. at work except case 25 , the widow of an asbestos $\frac{\pi}{\sigma}$ worker who for a period of three years returned from $\varrho$ work with asbestos dust on his hair and shoes. ळ The duration of exposure varied widely, the majority $\vec{O}$ being exposed for many years but seven patients only for five years or less. The concentration of $\vec{\omega}$ asbestos dust experienced by the patients was? generally low. Most had either been users of asbestos? insulation materials or had worked at other jobs 요 beside insulation workers who were using asbestos.

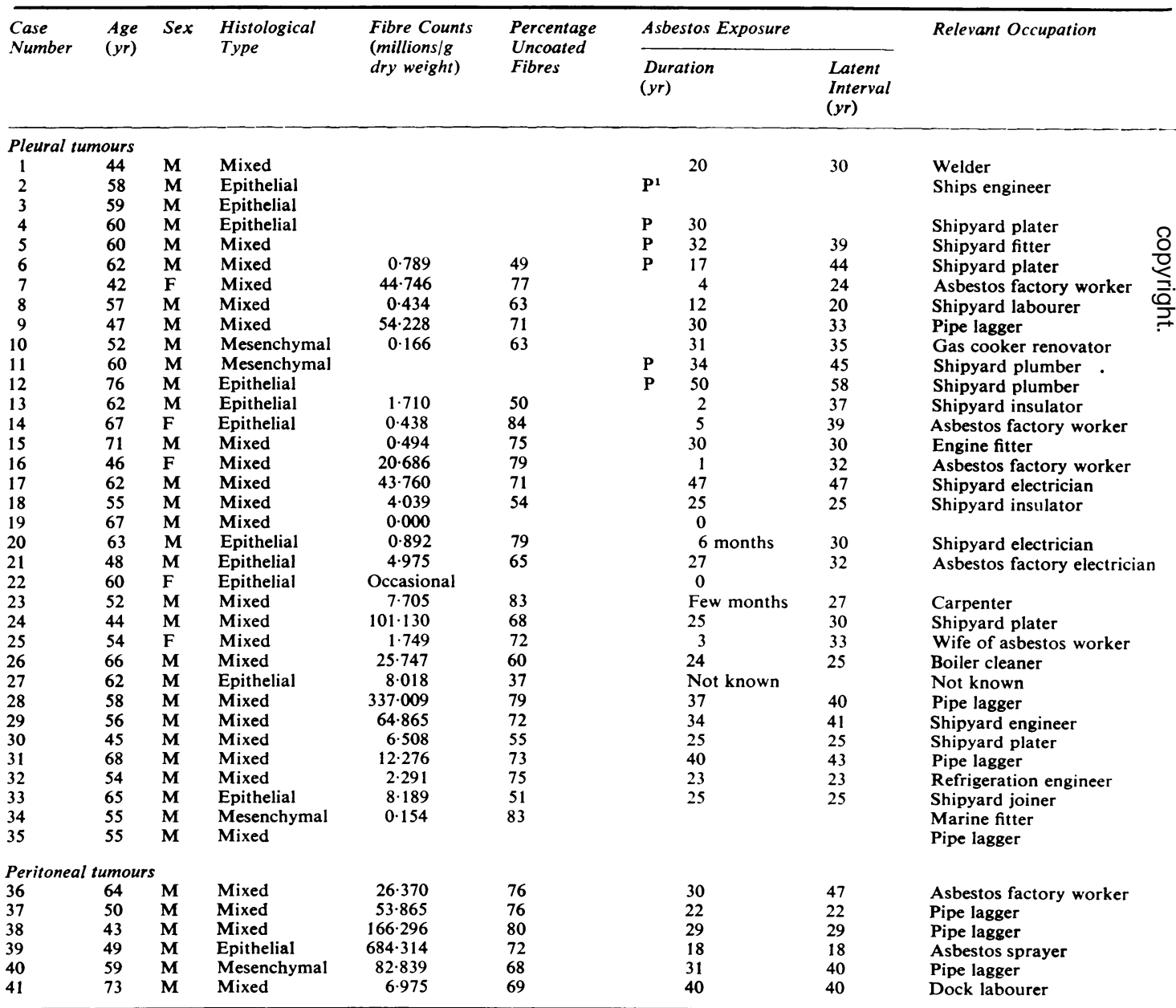

Table I Pathological type, asbestos fibre counts, and exposure to asbestos in cases of mesothelioma 
Only four patients had worked in an asbestos factory.

Group 2 contains six patients who were probably exposed to asbestos. Cases 5, 6, 11, and 12 had occupations in which incidental exposure to asbestos dust must almost certainly have occurred, but the relatives could not definitely confirm this. Case 4 spent 30 years as a shipyard plater. Case 2 was a retired ship's engineer-an occupation with a high probability of intermittent exposure during repair of insulation. Asbestos exposure in cases 6,11, and 12 was confirmed by the presence of asbestos bodies in lung sections, but adequate lung tissue was not available for cases 2,4 , and 5 .

Group 3 contains two individuals. Case 22, for whom a full history was available, had never worked with asbestos or held any job where incidental exposure seemed likely. Case 19 had a vague history of brief exposure some 10 years before death but this could not be confirmed and he has been counted as 'not exposed'.

Thus, out of the 40 patients for whom occupational data are available, $32(80 \%)$ had definite exposure to asbestos, six (15\%) had probable exposure, and two (5\%) had no known esposure. The mean latent interval (time elapsing between first exposure to asbestos and development of mesothelioma), combining 'definite' and 'probable' exposure, was 34 years (range 18 to 58 years). No patient had pure exposure to any one mineral variety of asbestos.

Coated fibres were found histologically in 36 $(92 \%)$ of the 39 cases for which sections of lung were available. Fibres were scanty in 24 cases and numerous in 12. Fibres were numerous in a higher proportion of peritoneal mesotheliomas (five out of six) than of pleural mesotheliomas (seven out of 30). Asbestosis was absent in 16 of the cases showing coated fibres in lung sections. Slight asbestosis (as defined by Beattie and Knox, 1961) was present in 14 cases, moderate asbestosis in five cases, and severe fibrosis in only one case. Asbestosis was moderate or severe in a higher proportion of peritoneal mesotheliomas (four out of six) than of pleural mesotheliomas (two out of 30). In contrast to the findings of Thomson (1962), mild asbestosis showed no predilection for the basal subpleural regions of the lungs.

When histological and occupational findings are combined for all 41 cases of mesothelioma, 39 $(95 \%)$ had definite or probable asbestos exposure.

\section{Asbestos fibre counts}

Total fibre counts and proportions of uncoated fibres are shown in table I. No fibres were identified in case 19 and only occasional fibres, including coated fibres of typical appearance, were detected in case 22. Neither of these patients had a history of asbestos exposure or showed any coated fibres in lung sections.

There was a very wide range of fibre counts in the remaining cases, extending from 154 thousand to 684 million total fibres per gram dry weight. Uncoated fibres usually outnumbered the coated fibres and comprised 50 to $80 \%$ of the count. No relationship was found between the latent period of the mesothelioma and the total fibre count (table II).

\begin{tabular}{lcl}
\hline $\begin{array}{l}\text { Total Fibre Count } \\
\text { (millions/g dry weight) }\end{array}$ & $\begin{array}{l}\text { No. of } \\
\text { Cases }\end{array}$ & $\begin{array}{l}\text { Mean Latent } \\
\text { Period }(\boldsymbol{y})\end{array}$ \\
\hline Less than 1 & 6 & $34 \cdot 7 \pm 5 \cdot 9$ \\
$1-9 \cdot 9$ & 9 & $30.6 \pm 8 \cdot 0$ \\
$10-99$ & 10 & $35 \cdot 3 \pm 9 \cdot 1$ \\
100 and over & 4 & $29 \cdot 3 \pm 9 \cdot 0$ \\
\hline
\end{tabular}

Table II Total asbestos fibre count related to the length of the latent period in mesothelioma cases

\section{MATCHED CONTROL PATIENTS}

A definite history of asbestos exposure was obtained in 12 of the 56 control patients (table III). Exposure was usually brief or intermittent and was often incidental to the patient's work, eg, a shipyard plater working beside pipe laggers. In half of the affected patients, the exposure was mild or even trivial, eg, a farmer roofed his chicken coops with asbestos.

\begin{tabular}{lll}
\hline Asbestos Exposure & Control Patients & $\begin{array}{l}\text { Mesothelioma } \\
\text { Patients }\end{array}$ \\
\cline { 2 - 3 } & No. & No. \\
\hline None known & $33(59 \%)$ & $2(8 \%)$ \\
Definite & $12(21 \%)$ & $19(70 \%)$ \\
Probable & $11(20 \%)$ & $6(22 \%)$ \\
Definite + probable & $23(41 \%)$ & $25(92 \%)$ \\
\hline
\end{tabular}

Table III History of asbestos exposure in 27 meso-

thelioma patients and in 56 age- and sex-matched control patients ${ }^{1}$

${ }^{1}$ No history available in one mesothelioma patient for whom controls were selected.

Eleven further patients had a history of work with a strong possibility of exposure to asbestos, often incidental, although the relatives could not say for certain that exposure had occurred, and these patients have been counted as having had 'probable' exposure. Some such individuals had worked for a few years in a shipyard, in trades known to involve incidental asbestos exposure.

The remaining 33 control patients had no history of asbestos exposure or of any occupation in which incidental exposure seemed likely. 
Thus there was definite asbestos exposure in 12 out of 56 controls $(21 \%)$ and definite or probable exposure in 23 out of 56 controls ( $41 \%)$. When these figures are compared (table III) with corresponding figures for mesothelioma propositi (27 in number since no history was available for case 3 ) there is a statistically highly significant difference whether the 'definite exposure' groups $\left(\chi^{2}=16 \cdot 6, \mathrm{P}<0.001\right)$ or 'definite' plus 'probable' exposure groups $\left(\chi^{2}=17 \cdot 8, \mathrm{P}<0.001\right)$ are compared.

\section{ROUTINE NECROPSIES}

A full account of the incidence of asbestos bodies in lung smears at routine necropsy has been published (Ashcroft, 1968a). A total of 311 smear cases was then described but one of these, a case of mesothelioma with positive smear, has been transferred from the smear group to the mesothelioma series (case 6). Coated fibres were found in basal lung smears in $62(20 \%)$ out of 310 necropsies in patients aged over 15 years $(25.1 \%$ of 195 males and $11.3 \%$ of 115 females). They were scanty (up to 34 per smear) in 45 cases, and numerous (over 170 per smear) in 17 cases. Information about occupation was obtained for 53 of the smear-positive patients and $30(57 \%)$ were definitely or probably exposed to asbestos. Among those with numerous coated fibres in the smear, 13 out of $15(87 \%)$ received definite or probable exposure to asbestos at work. (Owing to confusion of two cases with similar serial numbers, the previously reported proportion of 12 out of 14 was incorrect.) Comparison of smears and $6 \mu$ histological sections in smear-positive cases indicated that the smears were a more reliable means of detecting scanty coated fibres than the sections.

\section{Comparison with mesothelioma cases}

The sex ratio of the routine necropsy cases differs widely from that of the mesothelioma cases, the mesothelioma group being predominantly male $(\mathrm{M}: \mathrm{F}=7 \cdot 2: 1)$ whereas the control group is more evenly balanced $(M: F=1 \cdot 7: 1)$. Since female mesothelioma cases are few, however, the difficulty can be overcome by omitting all female cases and comparing male mesothelioma and malecontrol cases only. There was no significant difference in age distribution of males between controls and mesotheliomas. The incidence of coated fibres in lung sections of male mesothelioma cases $(94 \%)$ was much greater than that in lung smears of male routine necropsies $(25 \%)$ and statistically the difference is highly significant $\left(\chi^{2}=47.8 ; \mathrm{P}<0.001\right)$.

Fibre counts in routine necropsies

Fibre counts obtained in nine cases showing numerous coated fibres in lung smears ( $\mathrm{N}$-fibre cases) and in nine cases with one coated fibre per lung smear (1-fibre cases) are given in table IV. The $\mathrm{N}$-fibre cases showed total, uncoated, and coated fibre counts comparable with those of most mesothelioma cases showing scanty coated fibres in lung sections.

Only two of the 1-fibre cases possessed fibre sufficiently numerous for practicable counting, one of these giving the remarkably high total count of 7.76 million fibres. Five other cases produced occasional coated and uncoated fibres, while no fibres at all were detected in the last two cases.

No fibres were detected in 17 of the 30 samples from smear-negative cases. Occasional fibres were found in 10 cases and the remaining three cases gave total counts of $0.298,0.104$, and 0.061 millions

\begin{tabular}{|c|c|c|c|c|c|}
\hline \multirow{2}{*}{$\begin{array}{l}\text { Coated Fibres } \\
\text { in Lung Smear }\end{array}$} & \multirow{2}{*}{$\begin{array}{l}\text { Smear Case } \\
\text { No. }\end{array}$} & \multicolumn{3}{|c|}{ Fibre Count (millions/g dried tissue) } & \multirow{2}{*}{$\begin{array}{l}\text { Percentage Uncoated } \\
\text { Fibres }\end{array}$} \\
\hline & & Total & Uncoated & Coated & \\
\hline 428 & 1 & 0.435 & 0.094 & 0.341 & 22 \\
\hline 912 & 2 & 0.489 & $0 \cdot 112$ & 0.377 & 23 \\
\hline 513 & 3 & $1 \cdot 322$ & 0.762 & 0.560 & 58 \\
\hline 855 & 4 & $2 \cdot 667$ & $1 \cdot 146$ & $1 \cdot 521$ & 43 \\
\hline 855 & 5 & $3 \cdot 227$ & $2 \cdot 100$ & $1 \cdot 127$ & 65 \\
\hline 3363 & 6 & $3 \cdot 536$ & $1 \cdot 196$ & $2 \cdot 340$ & 34 \\
\hline 912 & 7 & $4 \cdot 136$ & 1.707 & $2 \cdot 429$ & 41 \\
\hline 855 & 8 & $5 \cdot 645$ & 3.035 & $2 \cdot 610$ & 54 \\
\hline 570 & 9 & $7 \cdot 171$ & $2 \cdot 859$ & $4 \cdot 312$ & 40 \\
\hline 1 & 10 & $7 \cdot 760$ & $3 \cdot 851$ & 3.909 & 50 \\
\hline 1 & 11 & 0.995 & 0.492 & 0.503 & 49 \\
\hline 1 & 12 & Occasional & Occasional & Occasional & \\
\hline 1 & 13 & Occasional & Occasional & Occasional & \\
\hline 1 & 14 & Occasional & Occasional & Occasional & \\
\hline 1 & 15 & Occasional & Occasional & Occasional & \\
\hline 1 & 16 & Occasional & Occasional & Occasional & \\
\hline 1 & 17 & None & & & \\
\hline 1 & 18 & None & & & \\
\hline
\end{tabular}

Table IV Fibre content of lung specimens from routine necropsy cases with lung smears positive for coated fibres 
per gram respectively, with, on average, $68 \%$ of uncoated fibres. Coated fibres were found in eight out of 15 males and five out of 15 females.

\section{Discussion}

\section{DIAGNOSIS}

The principal difficulty in the pathological diagnosis of diffuse malignant mesothelioma of pleura or peritoneum lies in distinguishing the condition from metastatic carcinoma, spreading from a primary tumour in lung or elsewhere. The diagnostic criteria used in this study were based initially on the work of Campbell (1950), Godwin (1957), and McCaughey (1958). Further valuable descriptions of the pathological features of mesothelioma have been given by Hourihane (1964), McCaughey (1965), Churg, Rosen, and Moolten (1965), Webster (1965), Whitwell and Rawcliffe (1971), and the UICC Working Group on Asbestos and Cancer (1965).
The most important criteria were: (1) Necropsy should fail to demonstrate any other primary malignant tumour from which the serosal growth could have metastasized. (2) The tumour should show microscopic appearances in keeping with those described for mesothelioma.

Necropsy examination was carried out in all cases in this series, and none showed a primary tumour of the viscera.

\section{Gross appearance}

Previous writers have emphasized the diagnostic importance of diffuse involvement of the affected pleurae and all but three of the present series of pleural mesothelioma showed diffuse thickening, usually with involvement of the interlobular fissures and often obliterating the pleural cavity (fig 1). However, the gross appearance of neoplastic pleural thickening is an unreliable guide to the nature of the tumour. Figure 2 shows a pneumonectomy

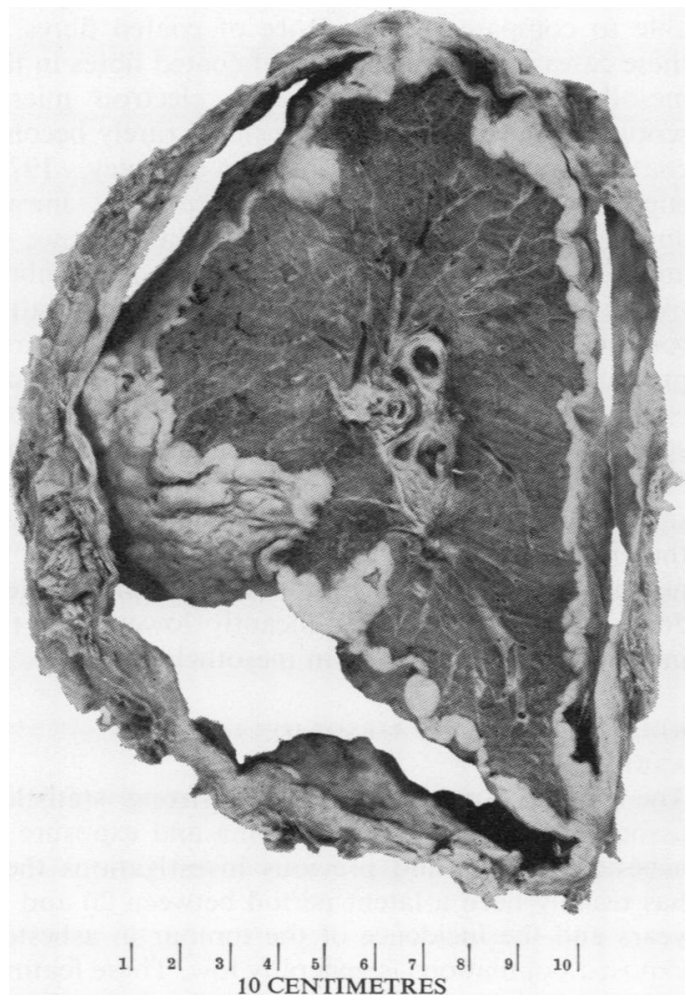

Fig 1

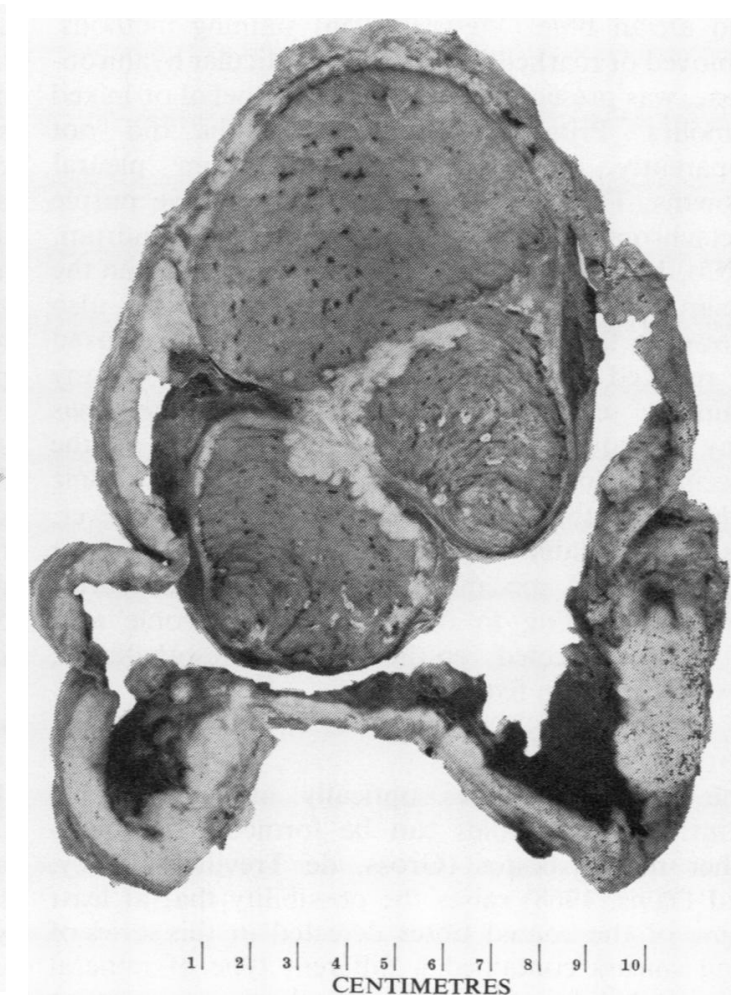

Fig 2

Fig 1 Sagittal slice of a pleuropneumonectomy specimen (case 16). Mesothelioma involves the visceral and parietal pleural surfaces, which have fused at the apex and the base of the lung.

Fig 2 Slice of a pleuropneumonectomy specimen in which metastatic carcinoma diffusely involves the pleural surfaces and closely mimics a mesothelioma. 
specimen with diffuse pleural tumour closely resembling a malignant mesothelioma. Histologically this tumour was a metastatic mucin-secreting adenocarcinoma. By contrast, the tumours of three histologically characteristic mesotheliomas took the form of scattered and confluent plaques on the visceral and parietal pleurae.

\section{Microscopic appearance}

The diagnostic importance of a mixed epithelial and mesenchymatous structure has been repeatedly stressed by previous writers. Twenty-five cases in this series showed such a structure. In addition there was usually much variability in the architecture of purely epithelial or mesenchymal tumours.

Considerable importance was attached to the histochemical demonstration of hyaluronidaselabile mucopolysaccharide within the lumens of tumour tubules or spaces (Wagner, Munday, and Harington, 1962). Secretion negative to the periodic acid Schiff (PAS) reaction but giving positive reactions with the colloidal iron (Mowry, 1958) and alcian blue (Mowry, 1956) staining methods, removed or markedly reduced by testicular hyaluronidase, was present in 29 out of 37 epithelial or mixed tumours. Primary peritoneal growths did not apparently differ histochemically from pleural growths. The secretion in many cases gave purple metachromasia with Azur A (Kramer and Windrum, 1955), but this reaction was less consistent than the alcian blue or colloidal iron. Many cases also showed a faint reaction with mucicarmine, removed or reduced by hyaluronidase. The absence of any stainable secretion in eight mixed mesotheliomas may be attributable to primary fixation of the specimens in formol saline, in which hyaluronic acid is soluble (Wagner et al, 1962). However, residual stainable material was found in many other formalin-fixed specimens, and it is always worthwhile attempting to demonstrate hyaluronic acid in any suspected epithelial-type mesothelioma, despite formalin fixation.

\section{ROUTINE NECROPSIES}

The fact that bodies optically indistinguishable from asbestos bodies can be formed from fibres other than asbestos (Gross, de Treville, Cralley, and Davis, 1968) raises the possibility that at least some of the coated fibres detected in this series of lung smears contained a different type of mineral fibre and did not necessarily indicate exposure to asbestos. 'Pseudo-asbestos bodies', with a black central fibre, were specifically ignored when examining smears, but bodies derived from substances such as glass fibre, silicon carbide, filamentous aluminium silicate, and talc could be confused with coated asbestos fibres. However, bodies derived from glass, talc, or diatomaceous earth are most unlikely to have produced false-positive smears in this series (Ashcroft, 1968b). Filamentous aluminium silicate is used as a thermal insulation material for specialized purposes but it only began to be used in Great Britain towards the end of the period when this series of lung smears was being collected. On Tyneside fibrous silicon carbide is used only in tiny experimental quantities.

On the other hand, the coated and uncoated fibres extracted from lung tissue in routine necropsies were indistinguishable from fibres recovered from the lungs of patients with known exposure to asbestos. In some specimens thicker uncoated fibres were birefringent in polarized light - a feature of asbestos fibres. More than half of the patients for whom an occupational history is available had either worked with asbestos or had worked where incidental exposure to asbestos is virtually certain. It is thus likely that the vast majority of smear-positive cases had been exposed to asbestos and it is justifiable to compare the incidence of coated fibres in these cases with the incidence of coated fibres in the mesothelioma cases. Moreover, electron microscopic evidence that chrysotile fibres rarely become coated after inhalation in man (Pooley, 1972 suggests that asbestos bodies detected in smears. and sections are likely to indicate the presence of amphibole fibres. The detection of coated fibres by tissue digestion in 13 out of 30 smear-negative routine necropsy cases indicates that the true proportion of fibre-containing routine necropsies is higher than that initially estimated. Fifteen specimens came from male patients and 15 from female patients and are assumed to represent random samples of the necropsies surveyed. On this basis the true incidence of coated fibres in the routine necropsy population of both sexes is approximately $56 \%$, but this is still significantly lower than the incidence of coated fibres in mesotheliomas.

\section{RELATIONSHIP OF MESOTHELIOMA TO} ASBESTOS

The present studies indicate a strong statistical association between mesothelioma and exposure to asbestos. In this and previous investigations there has usually been a latent period between 20 and 60 years and the incidence of the tumour in asbestosexposed populations is generally low. These features are compatible with the hypothesis that asbestos acts as a carcinogen of low potency for the mesothelial cells, tumours appearing only in the most susceptible individuals after a long latent period.

A possible objection lies in the lack of relationship between the dose of asbestos, as judged by fibre 
counts in lung tissue, and the latent period of the mesothelioma (table II) since, in experimental carcinogenesis, increasing the dose of a carcinogen causes tumours to appear earlier (Bryan and Shimkin, 1943). A similar objection has been made with regard to the effects of tobacco smoke in lung cancer (Passey, 1962). Kreyberg (1965), however, has shown, with reference to tobacco smoking, that an apparent lack of relationship between dose and latent period can occur with a weak carcinogen, because of the intervention of deaths from other causes. Similar considerations may well apply to asbestos and mesothelioma, particularly as exposure sufficiently severe to cause clinical asbestosis may lead to death of the patient from cor pulmonale or bronchogenic carcinoma within the latent period required for mesothelioma.

\section{ASBESTOS IN THE GENERAL POPUlation}

There is ample evidence from surveys of routine necropsies that a substantial number of modern city dwellers have coated fibres in their lungs and in Newcastle these are probably asbestos fibres. The question therefore arises whether people so affected are at risk of developing malignant mesothelioma (Thomson, Kaschula, and MacDonald, 1963).

The Newcastle routine necropsies showing coated fibres fell into two groups: $(a)$ those with numerous coated fibres in lung smears and $(b)$ those in whom fibres were detected only by tissue maceration or appeared in small numbers in lung smears. Patients of group b out-numbered those of group a by approximately 9 to 1 . Pulmonary fibre counts in patients of group a gave results similar to those obtained in many mesothelioma patients. Lung tissue from patients in group b usually yielded on analysis only 'occasional' fibres or numbers of fibres considerably lower than patients in group a. By contrast, 29 out of 31 mesothelioma cases had fibre concentrations equal to or greater than those of group a patients, while only one mesothelioma case had 'occasional' fibres on analysis. A further mesothelioma case yielded no pulmonary fibres at all and presumably had a spontaneous tumour unrelated to exposure to asbestos. Thus, as judged by numbers of pulmonary asbestos fibres, persons with group $b$ levels of exposure have a very small chance of developing pleural mesothelioma compared with people having group a exposure.

If it is assumed that the incidence of pulmonary asbestos bodies throughout Tyneside is the same as that in routine necropsies in Newcastle, ie, approximately $5 \%$ group a exposure and $50 \%$ group b exposure, then the population of Tyneside aged over 15 years, which numbers approximately a million (calculated from the Sample Census, 1966), will include about 50000 persons with group a exposure and 500000 with group b exposure. Only 38 cases of mesothelioma, however, are known to have come to necropsy between 1968 and mid-1969 (the other three cases in the series came from beyond the Tyneside area). Even if six probable cases excluded from the present investigation through lack of necropsy, and two further cases dying in the relevant period, which have recently come to my notice, are included, Tyneside has produced fewer than 50 cases of mesothelioma of pleura or peritoneum over a period of 12 years. These cases represent less than $0.1 \%$ of persons apparently at risk as a result of the asbestos content of their lungs (group a exposure), suggesting that some other factor in addition to the presence of asbestos may be concerned in the genesis of mesothelioma. Tobacco smoking seems unlikely to be involved (McEwen et al, 1970). The occupational data for routine necropsies indicate that a large majority of group a patients had definite or probable exposure to asbestos at work, while those with no known source of exposure generally fell into group b. This suggests that, on Tyneside at least, exposure to asbestos comparable to that of most cases of mesothelioma has usually occurred through occupational exposure rather than through general asbestos contamination of the urban environment. If urban air is to remain safe, however, present and future pollution by asbestos must be rigorously controlled.

I am indebted to Professor A. G. Heppleston for his continuing interest and for valuable criticism during this work. My thanks are also due to Professor D. J. Newell for statistical advice, to $\mathrm{Mr} \mathrm{J}$. Maclennan, Mr J. Stewart, and Mr. A Harvey for histochemical and other technical assistance, to Miss J. Ward and Mrs A. Lancaster for assistance in interviewing patients' relatives, and to the many pathologists and clinicians who gave me access to their material and records.

\section{References}

Ashcroft, T. (1968a). Asbestos bodies in routine necropsies on Tyneside: a pathological and social study. Brit. med. J., 2, 614-618.

Ashcroft, T. (1968b). Asbestos bodies. Brit. med. J., 2, 696-697.

Ashcroft, T. (1973). A comparison of asbestos exposure in cases of diffuse mesothelioma and in matched control cases. Proc. Second Internat. Conf. Biol. Effects of Asbestos. Dresden 1968, p. 296.

Ashcroft, T., and Heppleston, A. G. (1970). Mesothelioma and asbestos on Tyneside. A pathological and social study. In Pneumoconiosis. Proceedings of the 3rd International Conference, Johannesburg, 1969: edited by H. A. Shapiro, pp. 177-179. Oxford University Press, Cape Town.

Ashcroft, T., and Heppleston, A. G. (1973). The optical and electrcn microscopic determination of pulmonary asbestos fibre concentration and its relation to the human pathological reaction. J. clin. Path., 26, 224-234.

Beattie, J., and Knox, J. F. (1961). Studies of mineral content and particle size distribution in the lungs of asbestos textile workers. 
In 'Inhaled particles and vapours', edited by C. N. Davies, pp. 419-433. Pergamon Press, Oxford.

Bryan, W. R., and Shimkin, M. B. (1943). Quantitative analysis of dose-response data obtained with three carcinogenic hydrocarbons in strain C3H male mice. J. nat. Canc. Inst., 3, 503-531.

Campbell, W. N. (1950). Pleural mesothelioma. Amer. J. Path., 26, 473-487.

Churg, J., Rosen, S. H., and Moolten, S. (1965). Histological characteristics of mesothelioma associated with asbestos. Ann. N.Y. Acad. Sci., 132, 614-622.

Elmes, P. C., McCaughey, W. T. E., and Wade, O. L. (1965). Diffuse mesothelioma of the pleura and asbestos. Brit. med. J., 1, 350-353.

Godwin, M. C. (1957). Diffuse mesotheliomas with comment on their relation to localised fibrous mesotheliomas. Cancer, 10 298-319.

Gold, C. (1968). The quantitation of asbestos in tissue. J. clin. Path., 21, 537 .

Gross, P., de Treville, R. T. P., Cralley, L. J., and Davis, J. M. G. (1968). Pulmonary ferruginous bodies. Arch. Path., 85, 539-546.

Hägerstrand, I., Meurman, L., and Ödlund, B. (1968). Asbestos bodies in the lungs and mesothelioma. Acta path. microbiol. Scand., 72, 177-191.

Hourihane, D. O'B. (1964). The pathology of mesotheliomata and an analysis of their association with asbestos exposure. Thorax, 19, 268-278.

König, J. (1960). Úber die asbestose. Arch. Gewerbepath. Gewerbehyg., $18,159-204$.

Kramer, H., and Windrum, G. M. (1955). The metachromatic staining reaction. J. Histochem. Cytochem., 3, 227-237.

Kreyberg, H. J. A. (1965). Empirical relationship of lung cancer incidence to cigarette smoking, and a stochastic model for the mode of action of carcinogens. Biometrics, 21, 839-857.

McCaughey, W. T. E. (1958). Primary tumours of the pleura. J. Path. Bact., 76, 517-529.

McCaughey, W. T. E. (1965). Criteria for diagnosis of diffuse mesothelial tumours. Ann. N.Y. Acad. Sci., 132, 603-613.

McEwen, J., Finlayson, Angela, Mair, A., and Gibson, A. A. M.
(1970). Mesothelioma in Scotland. Brit. med.J., 4, 575-578.

Mowry, R. W. (1956). Alcian blue technics for the histochemical 음 study of acidic carbohydrates. (Abstr.) J. Histochem. Cytochem., 4, 407.

Mowry, R. W. (1958). Improved procedure for the staining of acidic polysaccharides by Müllers colloidal (hydrous) ferric oxide. $J$. Lab. Invest., 7, 566-576.

Newhouse, M. L., and Thompson, H. (1956). Mesothelioma of pleura and peritoneum following exposure to asbestos in the London area. Brit. J. industr. Med., 22, 261-269.

Passey, R. D. (1962). Some problems of lung cancer. Lancet, 2, $107-112$.

Pooley, F. D. (1972). Electron microscope characteristics of inhaled chrysotile asbestos fibre. Brit. J. industr. Med., 29, 146-153.

van der Schoot, H. C. M. (1958). Asbestosis en pleuragezwellen. Ned. T. Geneesk, 102, 1125-1126.

Selikoff, I. J., Churg, J., and Hammond, E. C. (1965). Relation between exposure to asbestos and mesothelioma. New Engl. J. Med., 272, 560-565.

Thomson, J. G. (1962). Mesothelioma of pleura or peritoneum and limited basal asbestosis. S. Afr. Med. J., 36, 759-760.

Thomson, J. G., Kaschula, R. O. C., and MacDonald, R. R. (1963). Asbestos as a modern urban hazard. S. Afr. Med.J., 37, 77-81.

U.I.C.C. report and recommendations of the working group on $\infty$ asbestos and cancer (1965). Ann. N.Y. Acad. Sci., 132, 706-721. N

Wagner, J. C., Munday, D. E., and Harington, J. S. (1962). Histo- O chemical demonstration of hyaluronic acid in pleural mesotheliomas. J. Path. Bact., 84, 73-78.

Wagner, J. C., Sleggs, C. A., and Marchand, P. (1960). Diffuse pleural mesothelioma and asbestos exposure in the North Western Cape Province. Brit. J. industr. Med., 17, 260-271.

Webster, I. (1965). Mesotheliomatous tumours in South Africa: pathology and experimental pathology. Ann. N.Y. Acad. Sci., 132, 623-646.

Weiss, A. (1953). Pleurakrebs bei Lungenasbestose in vivo mor-

phologisch geiehert. Medizinische, 93-94.
Whitwell, F., and Rawcliffe, R. M. (1971). Diffuse malignant pleuro mesothelioma and asbestos exposure. Thorax, 26, 6-22. 